\title{
Crime and punishment
}

\section{A realistic group conflict approach to racial discrimination in hiring convicted felons}

\author{
Barry Goldman
}

University of Arizona, Tucson, Arizona, USA

Dylan Cooper

CaliforniaStateUniversityChannelIslands, Camarillo, California, USA, and

Tamar Kugler

Management and Organizations, University of Arizona, Tucson, Arizona, USA

\begin{abstract}
Purpose - A surprisingly large proportion of the working population of the USA consists of individuals with felony convictions. Moreover, the issue of employability of these individuals is compounded for minorities. This paper aims to present two experimental studies investigating whether minorities with felony backgrounds have a more difficult time being selected for employment than identically situated white applicants. The authors ground the paper in realistic group conflict theory. Results indicate discrimination is more acute against minorities with felony backgrounds than whites with the same background and shed light on the mechanisms leading to this discrimination. Theoretical and practical implications arediscussed.
\end{abstract}

Design/methodology/approach - This paper involves two experimental studies involving working adults engaging with realistic survey situations using mTurk.

Findings - Results of both studies indicate discrimination is more acute against minorities with felony backgrounds than whites with the same background, and shed light on the mechanisms leading to this discrimination.

Research limitations/implications - One limitation of the methodology is that the authors used fictional candidates and jobs. This may have led to understating the effects of discrimination on minorities because it allowed applicants to answer in socially desirable ways (e.g. absent of racial bias) without suffering any of the anticipated negative consequences of actually hiring individuals about whom they hold negative stereotypes.

Practical implications - This research has several important implications for practice. First, organizations should be keenly aware of the potential for subtle and unconscious bias to affect the job application process even among well-intentioned hiring managers. Second, as the bias is often triggered by threats, organizations should share with their employees the nature of the threat involved with former felons.

Social implications - Organizations should deliberately address issues associated with the use of criminal background checks. For many organizations, a felony conviction in an applicant's background automatically eliminates that person from employment. However, a substantial amount of the workforce now has a felony in their background. Indeed, the Equal Employment Opportunity Commission (2012) has issued guidelines that detail important factors that organizations should consider on a case-by-case basis when considering employment for former felons. Organizations may consider updating any blanket exclusions regarding the hiring of ex-felons - not only because it makes good policy but also because it may help the organization hire the best people.

Originality/value - This research studies an important - and growing - societal problem related to the hiring of convicted felons, and the related issue of racial discrimination that affects black convicted felons particularly hard. There has been very little work in the management area on this topic. Moreover, there has 
been very little work in all areas that includes experimental methods. The use of such methods is particularly useful to eliminate confounds found in field data.

Keyword Race

Paper type Research paper

Federal and state anti-discrimination laws have done much to promote equality in the workplace. However, one significant and remaining area for permissible discrimination (sometimes referred to as "rational, discrimination" Simonson, 2006) involves those with prior felony convictions. Those convicted of felonious crimes, implying violation of important social rules, are marked by our legal system for society's severe punitive treatment (prison, fines, etc.). Moreover, there are reasons to believe that the consequences that felons experience beyond the immediate court-imposed punishment ("collaterial consequences") may not be experienced equally. These collaterial consequences can include loss of voting rights, difficulty in acquiring loans and housing, as well as increased obstacles in securing employment. In the area of employment hiring, there are significant questions as to whether minorities with felony convictions are less likely to be hired compared with whites with identical felony convictions (Pager, 2003).

The particular question of racial disparities in the hiring of those with felony convictions, while virtually omitted from the management literature (for an exception, Levashina and Campion, 2009), has received attention from researchers in the areas of sociology and criminology (Decker et al., 2015; Pager, 2003, 2007). This research has been valuable in mapping out factors, including race, that affect the hiring of those with felony convictions. However, it is often based on audit or archival data that may lack the controls of experimental methods. Moreover, it has typically been presented without reliance on an established theoretical construct to support the findings.

In this paper, we extend the previous research as it relates to the hiring of minorities (versus non-minorities) with felony convictions. In doing so, we strive to make several contributions: we use experimental methods to exert greater control over the studies; we rely on realistic group conflict theory (RGCT), a theory that is well-suited to understanding competition between groups for scarce resources (e.g. a job); we extend RGCT in two ways by investigating whether its effects extend to situations when the resource at stake has only symbolic benefits to the respondent or a member of his/her group; and by investigating mechanisms through which discrimination occurs by whites against minority felons.

Background

During that past few decades, the US prison population has dramatically increased. Between 1980 and 2000, this population increased 400 per cent (from 300,000 to 1.2 million; Pastore and Maguire, 2006). The US Department of Justice estimates that approximately 9 per cent of all men will serve some time in federal or state prison (Bonzcar and Beck, 1997; BJS, 2016). For certain subgroups, the proportion is even higher. Nearly 30 per cent of African American men and 16 per cent of Hispanic men will serve a prison sentence at some time during their lives (Pastore and Maguire, 2006).

Given that the median time served for prisoners released during the late 1990s was just over two years, a large group of non-institutionalized men now have prison records and the felony[1] records that typically go along with it (Stoll, 2009). The number of Americans with a felony conviction amount to approximately 4 per cent of the unemployed (Holzer et al., 2004; Pager, 2007; Schmitt and Warner, 2010). The successful re-absorption of this growing ex-offender population has major policy implications because failure to do so is costly in 
terms of increased crime and criminal victimization in society, increased stress on limited government resources, and lost productivity (Holzer, 2009).

There are several reasons to expect that ex-felons may have difficulty securing future employment other than for reasons of discrimination: Felons' (on average) lower education, poor cognitive skills and other personal factors are likely to restrict future employment regardless of their criminal records (Stoll, 2009). Felons may suffer still further disadvantages because they often do not accumulate significant work experience while incarcerated and may instead experience an erosion of skills. Moreover, ties to legitimate employers are likely to be severed by an initial arrest and prison time. From employers' viewpoint, a criminal record may signal that the individual is untrustworthy, likely to steal, be violent or otherwise problematic. They may avoid such workers due to a perceived propensity to break rules, steal or harm customers, or because they fear lawsuits based on negligent hiring (Holzer et al., 2007).

Perhaps unsurprisingly, the unemployment rate among ex-prisoners is substantially higher than among those who were never incarcerated, with an estimated loss to GDP of 0.40.5 per cent resulting in a total cost to the US economy of \$57bn to \$65bn in 2008 (Harris and Keller, 2005; Schmitt and Warner, 2010). Freeman (1991), for example, found that incarceration led to a 15 to 30 percentage-point decline in subsequent employment rates. Grogger (1992) concluded that differences in incarceration rates between young white and young black men accounted for about one third of the black-white employment gap in the National Longitudinal Survey of Youth data.

Approximately 11.3 per cent of all men born in the USA in 2001 are projected to serve time in federal or state prisons compared to 3.6 per cent born in 1974 (Schmitt and Warner, 2010). However, these projections differ by race and ethnicity - with estimates of 28 per cent for black males, 16 per cent for Hispanic males and 4 per cent for white males (Bonzcar and Beck, 1997). The criminal background check, via public or private records or providers, provides a tool for employers to make informed decisions before hiring convicted felons. The use of background checks has dramatically increased in the past 10 years, probably because of increased availability and decreased costs associated with technological change (Levashina and Campion, 2009). Due to the disproportionate percentage of minorities with criminal records, a number of civil rights groups have objected to the rampant use of criminal background checks. Their call has been echoed by the federal Equal Employment Opportunity Commission (EEOC). Recently, the EEOC has taken this policy position a step further by pursuing several lawsuits intended to reduce discrimination against felons, especially minority felons (e.g. EEOC v. Freeman Companies, Federal District Court of Maryland, 2009, in which it alleged that the company used criminal background checks to "unlawfully deprive a class of Black, Hispanic, and male job applicants of equal employment opportunities.")

In recent policy guidance, the EEOC (2012) stated that organizations should be mindful that the issue of arbitrary elimination of those with felony records is contrary to its recommendation. It was particularly sensitive to automatic bars to employment for felony convictions to minorities, as they are several times more likely than whites to have felony convictions. Specifically, the EEOC observed that:

Arrest and incarceration rates are particularly high for African American and Hispanic men. African Americans and Hispanics are arrested at a rate that is 2 to 3 times their proportion of the general population. Assuming that current incarceration rates remain unchanged, about 1 in 17 White men are expected to serve time in prison during their lifetime; by contrast, this rate climbs to 1 in 6 for Hispanic men; and to 1 in 3 for African American men.(EEOC, 2012, Introduction) 
If blacks and other minorities have felonies in their background at rates much higher than whites, then a key question is whether white employers are less likely to hire these minorities than white applicants with similar records.

Prior research supports the conclusion that blacks (and other minorities) are more frequently denied jobs because of racial discrimination than white applicants (Decker et al., 2015; Goldman, 2001; Pager, 2003, 2007). However, it remains unclear whether illegal discrimination also occurs because felony convictions reduce black job applicants' employment opportunities more than they reduce white applicants' opportunities. The concern is not just that proportionately more minorities are denied jobs because of felony convictions than white applicants; this is potentially defensible because proportionately more minorities have felony convictions than whites. The potential concern is whether blacks with felony convictions are subject to further employment discrimination because of inappropriate and illegal racial (or outgroup) bias.

Existing research has been helpful in demonstrating the possible aggregate effects of felony convictions on labor market outcomes. However, it presents largely mixed results and fails to disentangle discrimination based on race from discrimination based on criminal conviction. For example, Pager (2003) used an audit methodology (four male auditors; two blacks paired together and two whites paired together, one in each pair claimed a criminal record; both members of each pair applied for the same job) to compare the percentage of applications that elicited callbacks from actual employers. The effects of auditor race on the percentage of applications receiving callbacks were large (and statistically significant), both for those with criminal backgrounds and those without criminal backgrounds. Only 14 per cent of the applications by the black auditor without a criminal record received callbacks, relative to 34 per cent of the applications by the white auditor with no criminal record. Moreover, the white auditor with a criminal record received more favorable treatment (17 per cent callbacks) than the black with a criminal record ( 5 per cent). The white auditor with a criminal record received more favorable treatment (17 per cent) that the black auditor without a criminal record (14 per cent). However, the reduction in callbacks due to a criminal background was larger for the white auditors than for the black auditors (17 and 9 per cent reduction for whites and blacks, respectively, although this interaction was not statistically significant), indicating that blacks are not hurt by a criminal conviction more than whites. A similar methodology was presented by Pager et al. (2009), for low paying jobs in NYC. Although the effect size for the black vs white differential appear substantially smaller in this study, the authors documented that blacks are penalized slightly more for having a felony conviction compared to whites. Decker et al. (2015) used an audit methodology similar to Pager (2003; Pager et al., 2009) as well as online correspondence to send resumes or job applications by email. With respect to the online correspondence portion of the study, Decker et al. (2015) report no negative effects of race/ ethnicity or of having a prison record on employment chances. The audit portion of their study did find that whites were the preferred job applicants in the food service sector among those with a criminal record, but, similar to Pager (2003), the reduction in favorable responses due to a criminal record was larger for whites than for blacks. Therefore, the existing literature presents a pattern of mixed results regarding the question of racial discrimination against applicants with felony convictions.

As interesting and provocative as these studies are, they are limited in at least four important ways that restrict their ability to support their conclusions: First, they are not designed in a way that rules out the possibility that its findings can be explained by "typical" racial discrimination as opposed to discrimination based on criminal convictions. To do this, a study would be required to have applicants with identical pertinent factors. 
Then, it would have to demonstrate that the reduction in desirability following a criminal conviction is larger for blacks than for whites (as shown above, this was true for only one out of the three studies). Second, the audit field study methodology includes by nature many uncontrolled variables that can present alternative explanations to the findings. Third, the studies do not control for the race of the employers who reviewed the applications. To the extent that the studies conclude differential treatment for applicants based on race, it would seem relevant that the race of the decision maker be controlled. Finally, the studies do not provide a theoretical explanation to further support the results. A theory provides a deductive basis for hypothesis prediction and a foundation to understand and organize the data. To address these issues, we use experimental studies in which important information about the applicants (qualifications, type of crime, format of application, etc.), as well as the race of the decision maker, are controlled. We ground our hypotheses in RGCT, a wellregarded social-psychological model of intergroup relations (Sidanius and Pratto, 1999) as a basis for understanding discrimination against minority felons (as compared to white felons) by white hiring managers.

Below, we describe two experiments to test whether minorities (here, blacks) with felony convictions in their backgrounds were penalized more in the hiring process for having such convictions, than whites with identical credentials. In the first study, we find that minorities (blacks) with a felony conviction are discriminated against when seeking a job. The second study tests the mechanisms that help to explain this discrimination. We propose a model (Figure 1) for understanding racial discrimination against minorities with felony convictions.

\section{Realistic group conflict theory}

In this investigation, we rely upon the framework of RGCT, which offers an explantion for intergroup hostility involving scarce resources (Sidanius and Pratto, 1999). We do not argue that RGCT is necessarily the only framework to explain conflict over employment issues between group members. However, unlike psychological models of prejudice, racism and discrimination that focus strictly on internal and psychodynamic processes within the individual, RGCT is a social-psychological model that emphasizes the individual's absorption of cultural and ideological norms and the larger social context. As such, RGCT proposes that relations between particular groups are based not only on reactions to the immediate conflict between group members but also by the history of interactions between the groups (Jackson, 1993).

RGCT is a fairly straightforward theory asserting that intergroup discrimination and prejudice result from groups being locked in competition over either real or symbolic

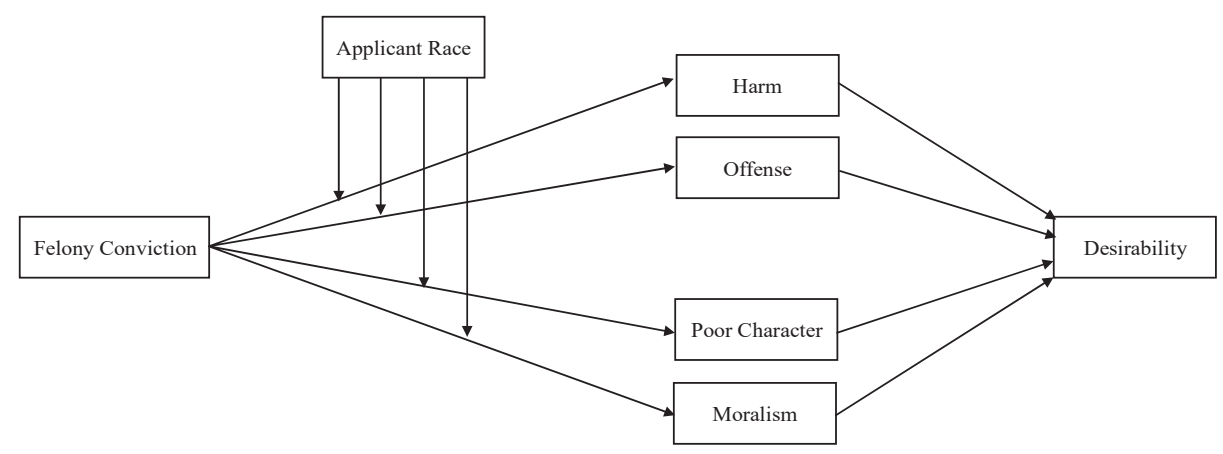

Figure 1. Theoreticalmodel 
resources that are in limited supply (Jackson, 1993; Sidanius and Pratto, 1999). The theory states that intergroup hostility is produced by the existence of conflicting goals (i.e. competition). For example, potential immigration host participants are more reluctant to help immigrants when they believe their own economic and power gains might be jeopardized by potential economic and power gains by the immigrants (Jackson and Essess, 2000). In this sense, it assumes that groups view these conflicts as a zero-sum game; that is, one group's gain is another group's loss. This translates into perceptions of group threat which, in turn, cause prejudice and discrimination against the outgroup (Campbell, 1965). RGCT is supported by a large body of research, across many different fields, using both surveys as well as field and lab experiments (Bobo, 1983; Sherif et al., 1961; Sidanius and Pratto, 1999). It has been brought into the management literature (Brief et al., 2005) to study racial diversity and work relationships but, as noted by Brief et al. (2005, p. 831), RGCT is still "underattended to by organizational scholars (at least in recent years)".

Since its inception, there has been remarkably little extension to the theory. The basic theory explains the reaction of group members to real competition over scarce resources (Bobo, 1988; Fiske and Ruscher, 1993; Jackson, 1993; Sidanius and Pratto, 1999). One area where there is debate among RGCT researchers is whether the ingroup (often, whites) attitudes toward outgroup members (often, blacks) are based primarily on prejudice, discrimination and racism or whether they are based primarily on self-interest (Bobo, 1983; Kinder and Sears, 1981). In the present study, we intend to extend RGCT by investigating discriminatory behavior by members of the ingroup when they do not personally benefit via significant tangible benefits.

Typically, studies of RGCT examine situations where a valued tangible or symbolic resource to the respondent's group is perceived to be threatened by the outgroup. The theory is based on two assumptions: that groups actually exist and have a history of shared identify and fate; and that these groups believe themselves to be in a zero-sum competition with other groups over valued resources (Sidanius and Pratto, 1999). We argue that once ingroups and outgroups are created through conflict and develop a shared identity, the intergroup conflict is generalized to settings where the rewards to the outgroup no longer directly deprives the ingroup. RGCT studies often involve a white ingroup and a black outgroup and result in discrimination or prejudice against the outgroup. We therefore argue that the negative behavior toward the outgroup exists even when the resource is not tangible, the actor cannot personally benefit in the real world from the resource, and the resource does not rise to the level of important symbolic valuesrepresented in prior studies (school busing in the 1980s, Bobo, 1983; Brief et al., 2005, p. 830, for research on symbolic competition). That is, when what is at issue is not so much a scarce and valued resource but only a relatively minor outcome to the respondents (non-managers), but one where different groups are in competition over it (in this case, a hypothetical job). We believe this will provide a more conservative test of RGCT by deemphasizing the importance of the scarcity of the resource at stake.

Social identity theory (Tajfel and Turner, 1979, 1986) is prevalent in the literature as the main alternative framework to RGCT. As noted by Brief et al. (2005), social identity theory is complementary to RGCT. It explains ingroup favoritism as based on a general desire for shared positive social identity. As Tajfel and Turner noted, "[... . the theoretical orientation to be outlined here is intended not to replace R.C.T. [RGCT], but to supplement it" (1979, p. 34). In elaborating social identity theory, Tajfel and Turner (1986) speculated on the effects of hierarchical social structures on intergroup discrimination. For example, they proposed that group conflict is likely to be increased when either group does not accept the legitimacy 
of their status distinctions (and minimized when both the superior and inferior groups accept the legitimacy of their status distinctions). As noted by Brief et al. (2005, p. 831):

Thus, it can be seen that realistic group conflict theory and social identity theory truly are complementary, with the latter providing a cognitive explanation of how intergroup conflict can arise (perceived or otherwise) and the former addressing the consequences of this conflict - the focus of attention here.

As with Brief et al. (2005), we rely primarily upon RGCT because this study focuses on the consequences of discrimination against convicted felons based on race.

\section{Study 1}

In Study 1, we investigate whether a prior felony conviction negatively affected black job applicants more than white job applicants when respondents rated applicants' desirability for a (fictional) job for which they are the hiring manager. Based on RGCT, we expected white respondents to prefer white applicants with felony convictions over black applicants with an identical resume and felony conviction. As noted earlier, RGCT explains ingroup preference for the distribution of limited resources to other ingroup members (over outgroup members) based on preference for one's ingroup (Bobo, 1983; Jackson and Essess, 2000). This is more likely to be the case in situations involving a scarce resource (such as a single job) because the outgroup's gain is likely to be viewed as the ingroup's loss. We therefore hypothesize the following:

H1. A felony conviction decreases applicant desirability.

H2. When rated by whites, black applicants are less desirable than white applicants with identical qualifications.

H3. When rated by whites, the effect of a felony conviction is moderated by the applicant's race such that the reduction in desirability for an applicant with a felony conviction compared to an identical applicant without a felony conviction is larger for black applicants than for white applicants.

\section{Method}

\section{Participants}

In total, 455 participants were recruited from Amazon Mechanical Turk (mTurk; Mason and Suri, 2012; Paolacci et al., 2010) for an experiment in which they would "play the role of a hiring manager in a company and review a job application." All participants were located in the USA and had a 95 per cent or higher work acceptance rate on mTurk. The experiment included three reading comprehension checks to eliminate participants who paid low levels of attention. In all, 301 participants passed those tests[2]. Participants were paid $\$ 0.75$ to complete the survey. To test our hypotheses, we retained the 247 participants who selfidentified as white as our final sample. In total, 114 (46 per cent) of these participants were female. Participants' age ranged from 20 to 72 years, with a mean age of 37.23 years $(\mathrm{SD}=$ 11.94).

\section{Design}

The experiment employed a 2 (applicant race: black, white 3 (criminal background check: clean, felony, no check) between-subjects design, resulting in six experimental conditions with approximately 40-45 observations per condition. 


\section{Procedure}

Participants completed the experiment online (see Appendix A for all study materials.) They were asked to imagine that they were managers at a fictitious online university, had posted an advertisement for a Market Research Analyst position and would be reviewing an application for the position. Participants subsequently read a 100 -word job description and answered two reading comprehension questions related to the job description.

Participants then viewed a list of job applicants, read that they would rate the application of one of them and completed the applicant race manipulation described below.

Next, they were presented with the job description again, a 140-word applicant resume, the criminal background check manipulation (described below), and a measure of applicant desirability (also described below). These elements were presented in a single Web page so that participants could refer to the job description, resume and background check information when completing the measure of applicant desirability. No information about applicant race was available on this page and participants were not able to navigate back to previous pages.

Finally, participants provided a free-text explanation of their impression of the applicant, completed manipulation checks (applicant sex, race and years of experience) and completed a comprehension check. As aforementioned, those who failed to remember whether a criminal background check had been run and, if so, whether the results indicated a criminal conviction, were excused from the experiment. Participants concluded by providing demographic information.

\section{Applicant race manipulation}

The applicant's race was manipulated by displaying a photo of the applicant. First, a list of three applicants with names and photos of their faces was displayed. Participants were informed that they would review the job application of one person from the list. The first photo was of a white female. The second two photos were of a black male and a white male. Note that this display creates competition between the white (ingroup) applicants and the black (outgroup) participant for a single job, which should triggeringroup bias as described by RGCT. The photos of the males were matched in attractiveness based upon the results of a previous pilot study conducted on mTurk with 50 participants. Matching business attire was visible in both photos. The photos used in the study are available from the authors.

In the black applicant condition, the photo of the black male was displayed at the bottom of the list and the photo of the white male was displayed in the middle position. In the white applicant condition, the order of the photos of the male applicants was reversed. The applicant name and job application information were identical in both conditions.

On the next page of the experiment, participants were told that they would review the application of the displayed applicant and the photo of the black or white male was presented. If the participant viewed this page for more than $2.5 \mathrm{~s}$, the experiment autoadvanced to the next page. We based our decision to limit participants to $2.5 \mathrm{~s}$ on Ho et al. (2011) who reported that this limited time allowed automatic processing of decisions involving racial stereotypes. No racial cues were present in the remainder of the experiment and participants were not able to view previous pages.

\section{Criminal background manipulation}

The criminal background check results were manipulated in the job application. In the clean check condition, participants were told that a criminal background check found no record of any criminal convictions. In the felony conviction condition, participants were told that a criminal background check found one felony conviction for possession of a controlled 
substance with intent to distribute. The applicant had been sentenced to 10 months in federal prison, three years of probation and a $\$ 5,000$ fine. The date of the conviction was such that the applicant would have been released from prison within the current year. In the no-check condition, no information regarding a criminal background check was presented. All other job application information was identical in all three conditions. The employment dates in the resume did not include months, so that they could remain the same in all three conditions.

\section{Dependent measure}

Four items measured job applicant desirability. The items were, "How likely would you be to interview this applicant for a job?", "Overall, do you agree with the statement, "This applicant is well suited for the job'?", "Does this applicant meet your criteria for someone who should get an offer for this job?", and "Overall, do you agree with the statement, "This applicant's strengths outweigh his weaknesses'?". Responses were recorded on a sevenpoint scale of increasing desirability. The scale was uni-dimensional with good internal consistency $(a=0.94)$.

\section{Results and discussion}

T1 Table I shows the mean applicant desirability in each of the six experimental conditions.

The results were analyzed using a $2 \times 3$ between-subjects analysis of variance. The analysis shows no main effect of applicant race on applicant desirability $(\mathrm{M}=5.00$ and 5.06 for white and black applicants, respectively $\left(F(1,246)=0.56, p=0.49, \mathrm{~h}^{2}=0.00\right)$, rejecting $H 2$. There was, however, a significant main effect of criminal background check condition $(F(2,246)=$ $\left.56.68, p<0.001, \mathrm{~h}^{2}=0.32\right)$. Orthogonal planned contrasts found that the applicant with a clean check $(M=5.89, S D=1.03)$ was more desirable than the applicant with no check $(M=$ $5.49, S D=1.29, p<0.05)$ regardless of race and that these two applicants were more desirable than the applicant with a felony conviction $(M=3.76, S D=1.69, p<0.001)$. This result supports $H 1$.

Finally, the interaction between applicant race and criminal background check on applicant desirability was significant, $F(2,246)=3.52, p<0.05, \mathrm{~h}^{2}=0.03$. Consistent with $H 3$, the black applicant suffered a larger decrease in desirability than the white applicant when a background check showed a felony conviction.

Overall, we find that applicants with a prior felony conviction are rated as less desirable by white respondents. We report no main effect of race on rating of job applicants. This is likely due to socially desirable answering (Supphellen et al., 1997). There is, however, a significant interaction of applicant race and criminal background check results. Black applicants are penalized more (rated as significantly less desirable) for having a prior felony

\begin{tabular}{lccc}
\hline Condition & $n$ & Desirability & $S D$ \\
\hline Black, clean check & 39 & 6.04 & 0.87 \\
Black, no check & 42 & 5.78 & 0.99 \\
Black, felony conviction & 45 & 3.53 & 1.80 \\
White, clean check & 41 & 5.75 & 1.15 \\
White, no check & 41 & 5.19 & 1.50 \\
White, felony conviction & 39 & 4.02 & 1.54
\end{tabular}

Note: Desirability was recorded on a seven-point scale with higher scores indicating higher desirability

Table I. Study 1. Mean applicant desirability in each condition 
conviction than are white applicants. This interaction is consistent with observations that direct and obvious effects (like the main effect of race) are more sensitive to social desirable answering than complex effects (such as interactions).

\section{Study 2}

Study 1 did not measure mechanisms to better understand why respondents judge certain applicants as more desirable than others. Study 2 was designed to address this question, by considering the mechanisms that lead white hiring managers to rate job applications from an ingroup (white) candidate more favorably than applications from an outgroup (black) candidate when both have a felony conviction. There has been little research on ingroup bias that attempts to better understand the specific psychological mechanisms that allow ingroup members to justify differential treatment of outgroup members. One exception, Bobo (1983), explored reasons whites opposed school busing. He reported that whites opposed to busing were not more likely to display prejudice or intolerance to blacks, per se, but instead perceived busing as threatening important values (Kinder and Sears, 1981, for a counter argument). We believe that RGCT would benefit from additional investigation of the mechanisms that create discriminatory behavior, particularly when these mechanisms involve subtle differences in the differential treatment between the races.

To identify potential mechanisms, we began by focusing on justifications for treating minority applicants with felony convictions differently than white applicants with clean backgrounds. As RGCT has little to say as to the mechanisms of how members of an ingroup differentially treat outgroup members, we relied on the work of legal scholar Joel Feinberg (1984-1988) who developed a typology of reasons that governments punish lawbreakers. Broadly speaking, these can be viewed as moral (something is inherently immoral or offensive) or pecuniary (protection against harm).

Feinberg was a political and legal philosopher whose seminal work, the four-volume The Moral Limits of the Criminal Law (1984-1988), addressed the question of what criminal conduct the state should punish. Feinberg famously expanded the justification for statesanctioned criminal punishment beyond the accepted standard at the time that only punishment intended to address harm to others can be morally punished (Mill, 1859). In a famous thought experiment, Feinberg (1985) invites readers to an imaginary "ride on the bus" in which the observer experiences a series of harmless but increasingly offensive behaviors from others (e.g. scratching nails on slate, burning of the flag, public sex) to make the argument that some conduct is so offensive to reasonable people as to warrant statesanctioned punishment. As part of his justification, Feinberg rejected the assumption of psychological egoism that individuals only pursue self-interest, arguing that punishment should transcend just harm to self because humans are interested in more than narrow selfinterest (Feinberg, 2008). We adopt this perspective, widely viewed nowadays as "magisterial" (Jamieson, 2014, p. 168), to extend RGCT in part because it is consistent with our view that RGCT triggers negative reactions of ingroup members to outgroup members for reasons beyondself-interest.

Moreover, we extend this perspective to the work environment. We argue that some organizational managers choose to compound the adverse treatment that former felons have already received by deciding to not hire them. Such hiring managers may view the nonhiring of former felons as an extension of a complex network of societal punishment and, as evolutionary biologists argue, act on a cultural and genetic predisposition to punish cheaters because they represent a threat to social cohesion (Barkow et al., 1995; Cosmides and Tooby, 2016; Hoffman, 2014). Managers may also see former felons as potentially dangerous to the success of their organization and view non-hiring as a way to protect against this harm. 
Because Feinberg's typology has not been empirically tested previously, we surveyed 30 US adults online, soliciting (free-text) reasons for why they would be hesitant to hire job applicants with a felony conviction. The goal for this survey was twofold. First, we wanted to verify that Feinberg's categories corresponded to self-reported reactions to job applicants with felony convictions. This was indeed the case. The majority of the reasons given to not hire former felons were pecuniary, but moral reasons, especially related to taking offense to working with a criminal, were identified as well. Second, we hoped to discover whether people reported reasons beyond those proposed by Feinberg. We found one such category: concerns about poor character (e.g. propensity to violence, theft and unreliable behavior) were raised by many of the survey respondents.

Overall, we identified four reasons why hiring managers may consider applications from former felons inferior to those from candidates with clean criminal backgrounds. Harm is judgment that the applicant might harm the organization or the people in it. This could involve financial or reputation damage to the organization, as well as physical or psychological harm to other organizational members. This corresponds to Feinberg's (1985) category of "harm to others". Survey respondents indicated such concerns with comments like, "There could be financial risk to my company," and "If people found out, it could tarnish the reputation of my company." Offense is the judgment that other organizational members may be offended by hiring the applicant or being forced to work with him or her. This corresponds to Feinberg's (1985) "offense principle" and was revealed on the survey with objections such as, "It could cause problems with other employees." Poor character includes concerns about the applicant's character. Although this does not directly correspond to any of Feinberg's (1985) categories, it was revealed with survey comments such as "They may be less trustworthy in general." Finally, moralism consists of moral concerns on the part of the hiring manager about hiring the applicants. This corresponds to Feinberg's (1985) "legal moralism" and was revealed on the survey with comments such as, "I might not like what they did." Note that offense is related to the concerns of other organizational members while moralism is related to personal concerns.

RGCT (and the results of Study 1) suggest that these reasons are used differentially - for whites and minorities - with white hiring managers more likely to find minorities with felony convictions offensive to others, likely to cause harm, low in character and immoral as compared with whites with identical felony convictions. Study 2 is therefore designed to test the following thypotheses:

H4. When rated by whites, applicant race moderates the effect of felony conviction on four reasons to not hire an applicant: (a) harm, (b) offense, (c) poor character and (d) moralism, so that the difference in the rating for black applicants with and without a felony conviction is larger than the difference in ratings for white applicants with and without a felony conviction.

\section{Method}

\section{Participants}

In total, 319 adult participants were recruited from mTurk for a task in which they were told they would, "Review a job application and answer questions about why you would or would not hire the candidate." Twenty-one participants withdrew before completing the survey. The experiment included the same three comprehension checks as Study 1 and two attention check questions to eliminate participants who read or answered carelessly. The 96 participants who failed to answer all of these questions correctly were removed from the analysis. The experiment was successfully completed by 202 participants of whom 102 
(51 per cent) were female. They were paid $\$ 1.50$ to complete the experiment. Their age ranged from 18 to 68 years with a mean of $34.70(\mathrm{SD}=10.74)$. To test our hypotheses, we retained the 157 participants who self-identified as white as our final sample.

\section{Design}

The experiment employed a 2 (applicant race: black, white 2 (criminal background check: clean, felony) between-subjects design, resulting in four experimental conditions with 34-45 observations per condition.

\section{Procedure}

Participants completed the experiment online. They read the scenario and job description used in Study 1, answered simple comprehension check questions and then reviewed a job application including a resume and criminal background check. The resume was similar to that used in Study 1. Participants then completed measures of reasons why they would be willing or unwilling to hire the applicant (see Measures section below). They concluded by completing a manipulation check and a short demographic survey.

\section{Applicant race manipulation}

We manipulated applicant race through the photo and last name on the resume. The resume was described to participants as, "the applicant's online resume from LinkedIn.com" and was formatted similarly to those on this well-known professional networking website. Most importantly for this experiment, LinkedIn.com resumes prominently display a photo of the applicant. We used the same applicant photos as in Study 1. In addition, in the black applicant condition, the candidate's last name was Washington. In the white applicant condition, the last name was Walsh. These names were chosen because they were used predominantly by people self-identifying as black and white, respectively, in the 2000 US Census (USA Census Bureau, 2014).

To check that participants could recall the manipulation at the end of the experiment, they answered the item, "What was the applicant's race?" The possible answers were African American/Black, Asian, Hispanic, White and "I don't remember". In the black applicant condition, 97 of 99 ( 98 per cent) of the participants recalled the race correctly. In the white applicant condition, 104 of 105 (99 per cent) recalled it properly.

\section{Criminal background manipulation}

The manipulations for the felony conviction and clean background check conditions were the same as in Study 1. The no-check condition was not used. We removed from the analysis the six participants who did not recall whether the participant had been convicted of a felony (through one of the comprehension check questions discussed earlier) because this information was stated explicitly.

\section{Measures}

We measured four variables reflecting reasons why hiring managers may consider applications from former felons inferior to those from candidates with clean criminal backgrounds: harm, offense, poor character and moralism. Responses were recorded on a seven-point Likert scale with higher scores indicating higher agreement.

We developed three-item measures for each of these variable. See Appendix B for the full scale. The variables, as well as the items that measure them, were extracted and developed from the two sources discussed above: Feinberg (1985) and the qualitative study of 30 
participants who were asked to list three to five reasons why they would not be willing to hire a job applicant of unspecified race with an unspecified felony conviction. The initial scale had three to seven items in each variable measure. We then ran a trial of these items $(n=81)$. Participants in the trial were asked to rate how much they agreed that each item was a reason to not hire an applicant with a felony conviction. A confirmatory factor analysis was used to identify items to either eliminate or reword. Finally, we repeated the process $(n=100)$ to test the revised version. Although the chi-square test of fit of the final model is significant, the remaining fit statistics indicate acceptable fit for the participants of Study $2\left(x^{2}=122.56, d f=48, p<0.001 ; \mathrm{CFI}=0.97\right.$, TLI $=0.97, \mathrm{RMSEA}=0.09, \mathrm{SRMR}=$ 0.02 ; Hu and Bentler, 1999; Mathieu et al., 2006). We also created an overall reasons not to hire variable by averaging the four scales. This was justified because adding a higher-level factor to the CFA retained similar fit $\left(x^{2}=143.99, d f=50, p<0.001 ; \mathrm{CFI}=0.97, \mathrm{TLI}=0.96\right.$, RMSEA $=0.10$, SRMR $=0.03$ ).

\section{Results and discussion}

Table II presents the mean values of all the reasons to not hire in each of the four experimental conditions. The results were analyzed using a $\mathbf{k} 2$ between-subjects analysis of variance. Recall from Study 1 that discrimination against a black applicant with a felony conviction resulted in a significant interaction between the background check and the race of the applicant. We found that black applicants were penalized more for a felony conviction than white applicants with the same conviction. We tested a similar interaction here.

The test of the interaction between applicant race and criminal background check is reported in Table II. Consistent with our prediction of discrimination, the black applicant suffered a larger increase in the rating of two of the four reasons to not hire (harm, poor character) when a background check showed a felony conviction compared to the white applicant. The two other reasons, moralism and offense, showed an effect in the predicted direction but fell short of significance. The overall reasons not to hire variable also exhibited the significant interaction. To the extent that these reasons contribute to reducing an applicant's overall desirability, we can conclude that black applicants with a felony conviction are discriminated against in hiring, mainly because they are expected to cause more harm to the organization and to be of a poor character.

\begin{tabular}{lcccccc}
\hline Condition & $N$ & Harm & Poor character & Offense & Moralism & Overall \\
\hline Black, clean & 34 & $1.60(1.09)$ & $1.77(1.30)$ & $1.57(0.83)$ & $1.48(0.68)$ & $1.61(0.90)$ \\
Black, felony conviction & 45 & $3.73(1.33)$ & $3.75(1.21)$ & $4.04(1.27)$ & $2.96(1.38)$ & $3.62(1.12)$ \\
White, clean & 35 & $2.07(1.43)$ & $2.21(1.36)$ & $1.85(1.31)$ & $1.70(1.16)$ & $1.96(1.24)$ \\
White, felony conviction & 43 & $3.34(1.22)$ & $3.37(1.32)$ & $3.67(1.36)$ & $2.67(1.23)$ & $3.26(1.18)$ \\
$F$ & & 4.31 & 3.80 & 2.72 & 1.87 & 4.76 \\
$P$ & & 0.04 & 0.05 & 0.10 & 0.17 & 0.05 \\
$\mathrm{~h}^{2}$ & & 0.03 & 0.02 & 0.02 & 0.01 & 0.02
\end{tabular}

Notes: $S D$ in parentheses. $F$ statistic is for testing the interaction between applicant race and criminal background check condition, $d f=(1,156)$ for all comparisons. Responses were recorded on a seven-point Likert scale with higher scores indicating higher agreement

Table II.

Study 2. Mean endorsement of reasons to not hire the applicant in each condition 


\section{General discussion}

\section{Major findings}

In Study 1, we report an interaction between applicant race and criminal record on rated applicant desirability. While we document a decrease in desirability for all applicants with a felony conviction, consistent with our prediction of discrimination, the black applicant suffered a larger decrease in desirability than the white applicant when a background check showed a felony conviction. Thus, in this study, we confirmed that black job applicants with felony records do indeed have a more burdensome obstacle than comparable white applicants.

Study 2 investigates the mechanisms by which a felony conviction affects the rating of reasons not to hire applicants with a felony conviction. It also investigated whether race moderates the effect of a felony conviction on ratings of reasons not to hire applicants. Consistent with our prediction of discrimination, the black applicant (as compared to a white applicant) suffered a larger increase in two of the four reasons (harm and poor character) not to hire the applicant when a background check showed a felony conviction. Figure 1 presents the full model tested in both studies.

\section{Theoretical implications}

RGCT states that when members of an ingroup perceive a threat of loss to a scarce and valued resource, they increase their prejudice and adverse behavior directed toward an outgroup (Esses et al., 2010). Our study suggests that these differential effects of outgroup vices or ingroup virtues are evident even when the resource at stake is not a tangible resource that a group member can personally benefit from or an important group value, i.e. the preference for ingroup members exists even when what is at stake is a symbolic resource (in this case, a job which respondents knew did not really exist). Moreover, this preference for ingroup members exists even when among a pool of job applicants with generally "undesirable" job qualifications (i.e. felony convictions). This speaks to the robustness of the preference for ingroup members even when the resource involved is not very substantial. Future research may explore this further to determine the limits of this effect and to investigate whether the preference involves an exaggeration of outgroup vices or of ingroup virtues.

Campbell (1965, p. 289) also proposed that intergroup conflict increases as the conflicting groups have more in tangible gains at risk and that this in turn leads to a "magnification of outgroup vices" and also "exaggeration of ingroup virtues." Our study extends RGCT by investigating the mechanisms by which white respondents rationalize their preference for ingroup members. It suggests that the reasons not to hire differ by the race of the applicant with white respondents reporting that black applicants with felony convictions are more likely to be discriminated against because they are expected to cause more harm to the organization and to be of poorer character. The other two reasons, moralism and offense to others, showed an effect in the right direction that fell short of significance. These results suggest that ingroup members do indeed emphasize the "magnification of outgroup vices." Future research may further explore this relative preference for exaggeration of outgroup vices or of ingroup virtues.

A related question is whether the effects we found also exist with other minority groups (e.g. Hispanics) or whether they are isolated to blacks. It is possible that recent social movements, like Black Lives Matter, make whites both more publicly guarded in their expression of bias but more likely to activate them unconsciously. It is unclear whether the same effect will occur with Hispanics, with a less visible social movement. A related question is whether the results of this study would also hold if the raters were something other than whites. As noted, RGCT requires that the group members have a sense of shared 
identify and fate. Prior research states that minorities (such as blacks) have, perhaps, even more of a sense of shared identify and fate. Therefore, it would seem to follow that minority raters would have at least as strong a preference for other minority applicants over nonminority applicants.

\section{Practical implications}

This research has several implications for practice. First, organizations should be keenly aware of the potential for subtle and unconscious bias to affect the job application process even among well-intentioned hiring managers. Organizations should consider job training programs that extensively review the possibility of a double hurdle for minority job applicants with felony backgrounds, i.e. the criminal background as well any possible stereotypes that are triggered.

Second, as the bias is often triggered by threats, organizations should share with their employees the nature of the threat involved with former felons. As noted earlier in the paper, former felons constitute a much larger proportion of the working population than most people general assume. They are the great unseen in the workplace and general population. Most are non-violent but the unaddressed stereotype of a convicted felon is powerful and, if left unaddressed, can result in overt or covert fear that, in turn, can help trigger a plethora of stereotypes.

Finally, organizations should deliberately address issues associated with the use of criminal background checks on all applicants. For many organizations, the existence of a felony conviction (or, indeed, of any criminal conviction) in an applicant's background automatically eliminates that person from employment. However, as noted earlier, a substantial amount of the workforce now has a felony in their background. This serves as a modern-day Scarlett Letter ostracizing the former felon. As one former felon told the first author, "I committed a drug crime 30 years ago and was released from prison 22 years ago. When can I leave that behind?" Indeed, the EEOC (2012) has issued guidelines that detail important factors that organizations should consider on a case-by-case basis when considering employment for former felons. These factors include the nature and gravity of the offense, how much time has passed since the offense or completion of the sentence, and the nature of the job sought. Organizations may consider updating any blanket exclusions regarding the hiring of ex-felons - not just because it makes good policy, not only because it may be the moral thing to do but also because it may help the organization hire the best people.

\section{Limitations and further research questions}

The main limitation of our methodology is that we used fictional candidates and jobs, and this was known to the study participants. We have traded off realism in return for tight control over the information the participants receive, and ability to manipulate only the race and record of the applicant, without confounding other factors that could affect desirability. This may have led to understating the effects of discrimination on minorities because it allowed applicants to answer in socially desirable ways (e.g. absent of racial bias) without suffering any of the anticipated negative consequences of actually hiring individuals about whom they hold negative stereotypes. In fact, Study 1 found no effect of racial discrimination among job candidates when no criminal background check information was presented, despite widely documented racial effects in hiring. This suggests that discrimination against minorities with felony convictions may be higher than reported here. We therefore suggest that our findings should be evaluated within the context of the other empirical audit studies reviewed in the introduction. Further research should attempt to identify the interaction between a criminal background and race in a field experiment, with real jobs. 
Our studies referenced only male job candidates who were either black or white. Further research is required to test whether the same results hold for women candidates and minorities from other ethnic or racial groups. We selected black males as the focus minority group in our studies because they are the most incarcerated group in the USA and, hence, have the most to lose from the discrimination we describe. Whether black women and members of other minority groups (e.g. Hispanics) suffer similar discrimination is an open research question. It is possible that recent social movements, like Black Lives Matter, make whites more publicly guarded in their expression of bias but more likely to activate unconscious bias. This may not occur with Hispanic job applicants, with a less visible social movement.

Finally, in our two experiments, the candidates had been convicted of drug distribution. Future research should examine variance in racial discrimination by type of crime. Are certain crimes more associated by the public with whites versus blacks (e.g. perhaps tax evasion vs drug crimes) and is the reaction of hiring managers to applicants with stereotyping-triggering crimes affected by the type of crime? For example, would the reaction of a hiring manager to a black applicant convicted of tax evasion differ from that of a white applicant convicted of the same? Or, would the reaction differ for a black applicant convicted of a drug crime as opposed to tax evasion? There are reasons to think that the reaction may be harsher for a black applicant convicted of a crime more associated with the stereotype of a black felon. That is, attribution theory might suggest that external attributions might cause managers to more likely excuse a person from a crime not typically associated with that group. Conversely, the hiring manager is more likely to attribute internal attributions - and less likely to excuse - a person from a crime typically associated with that group (Ababneh et al., 2014; Ployhart and Ryan, 1997).

\section{Conclusion}

In this study, we investigated whether minorities (here, blacks) with felony convictions in their backgrounds were less likely to be hired for jobs than whites with identical credentials. In two studies, we established this to be the case. Moreover, the conservative measures and experimental methods provide a high degree of confidence in the results. Relying on RGCT and legal theory of punishments (Feinberg, 1985), we proposed and found that members of the white ingroup rationalize this discrimination by perceiving black felony applicants as having poorer character and being more likely to cause organizational harm. We also discussed the theoretical and practical implications of this study, as well as calling for further research in related areas.

\section{Notes}

1. A prison record is considered a "felony" when one is sentenced to a crime punishable by one or more years in prison.

2. We believe the relatively high failure rate is due to comprehension checks that required recalling the content of text read on the previous page. The checks, along with the number of participants who failed each, are presented in Appendix A.5.

\section{References}

Ababneh, K.I., Hackett, R.D. and Schat, A.C. (2014), "The role of attributions and fairness in understanding job applicant reactions to selection procedures and decisions", Journal of Business and Psychology, Vol. 29 No. 1, pp. 111-129. 
Barkow, J., Cosmides, L. and Tooby, J. (1995), The Adapted Mind: evolutionary Psychology and the Generation of Culture, Oxford University Press, Oxford.

BJS (2016), "Bureau of justice statistics", available at: www.bjs.gov/index.cfm?ty=tp\&tid=1

Bobo, L. (1983), “Whites' opposition to busing: symbolic racism or realistic group conflict?", Journal of Personality and Social Psychology, Vol. 45 No. 6, pp. 1196-1210.

Bobo, L. (1988), "Group conflict, prejudice, and the paradox of contemporary racial attitudes", in Katz, P.A. and Taylor, D.A. Taylor (Eds), Eliminating Racism, Plenum Press, New York, NY, pp. 85-114.

Bonzcar, T.P. and Beck, A.J. (1997), "Bureau of justice statistics special report, lifetime likelihood of going to state or federal prison, NCJ-160092", available at: https://bjs.gov/content/pub/pdf/ Llgsfp.pdf (accessed 14 June 2018).

Brief, A., Umphress, E., Dietz, J., Burrows, J., Butz, R. and Scholten, L. (2005), "Community matters: realistic group conflict theory and the impact of diversity", Academy of Management Journal, Vol. 48 No. 5, pp. 830-844.

Campbell, D.T. (1965), "Ethnocentric and other altruistic motives", in Levine, D. (Ed.), NE Symposium on Motivation, University of NE Press, Lincoln, NE, pp. 283-311.

Cosmides, L. and Tooby, J. (2016), "Evolutionary psychology: a primer", available at: www.cep.ucsb. edu/primer.html (accessed 14 June 2018).

Decker, S.H., Ortiz, N., Spohn, C. and Hedberg, E. (2015), "Criminal stigma, race, and ethnicity: the consequences of imprisonment for employment", Journal of Criminal Justice, Vol. 43 No. 2, pp. 108-121.

EEOC (2012), "Consideration of arrest and conviction records in employment decisions under title VII of the civil rights act of 1964", available at: www.eeoc.gov/laws/guidance/arrest_conviction.cfm (accessed 14 June 2018).

Esses, V.M., Jackson, L.M. and Bennett-AbuAyyash, C. (2010), "Intergroup competition", in Dovidio, J. F., Hewstone, M., Glick, P. and Esses V.M. (Eds), Prejudice, Stereotyping, and Discrimination, Sage, Los Angeles, CA, pp. 225-240.

Feinberg, J. (1984-1988), The Moral Limits of the Criminal Law, Oxford University Press, New York, NY.

Feinberg, J. (1985), Offense to Others. The Moral Limits of the Criminal Law, Oxford University Press, Oxford, Vol. 2.

Feinberg, J. (2008), "Psychological egoism”, in Feinberg, J. and Shafer-Landau, R. (Eds), Reason and Responsibility: readings in Some Basic Problems of Philosophy, Thomson Wadsworth, Belmont, CA, pp. 520-532.

Fiske, S.T. and Ruscher, J.B. (1993), “Negative interdependence and prejudice. Whence the affect?”, in Mackie D. and Hamilton D.L.(Eds), Affect, Cognition and Stereotyping: Interactive Processes in Group Perception, Academic Press, San Diego, CA, pp. 239-268.

Freeman, R.B. (1991), "Crime and the employment of disadvantaged youths", Working paper no. 3875, National Bureau of Economic Research Working Paper Series, Cambridge, MA.

Goldman, B. (2001), "Toward an understanding of employment discrimination-claiming: an integration of organizational justice and social information processing theories", Personnel Psychology, Vol. 54 No. 2, pp. 361-386.

Grogger, J. (1992), "Arrests, persistent youth joblessness, and black/white employment differentials", The Review of Economics and Statistics, Vol. 74 No. 1, pp. 100-106.

Harris, P.M. and Keller, K.S. (2005), "Ex-offenders need not apply: the", Criminal Background Check in Hiring Decisions", Journal of Contemporary Criminal Justice, Vol. 21 No. 1, pp. 6-30. 
Ho, A.K., Sidanius, J., Levin, D.T. and Banaji, M.R. (2011), "Evidence for hypodescent and racial hierarchy in the categorization and perception of biracial individuals", Journal of Personality and Social Psychology, Vol. 100 No. 3, pp. 492-506.

Hoffman, M.B. (2014), The Punishers Brain, Cambridge University Press, Cambridge.

Holzer, H.J. (2009), "Collateral costs: effect of incarceration on employment and earnings among young workers", in Raphael S. and Stoll, M.A. (Eds), Do Prisons Make Us Safer? the Benefits and Costs of the Prison Boom, Sage, Los Angeles, CA, pp. 239-268.

Holzer, H.J., Raphael, S. and Stoll, M. (2004), "Will employers hire former offenders? Employer preferences, background checks, and their determinants", in Pattillo, M., Weiman, D. and Western, B. (Eds), Imprisoning America: The Social Effects of Mass Incarceration, Sage, Los Angeles, CA, pp.205-234.

Holzer, H.J., Raphael, S. and Stoll, M. (2007), "The effect of an applicant's criminal history on employer hiring decisions and screening practices: evidence from los angeles", in Bushway, S., Stoll, M. and Weiman, D. (Eds), Barriers to Reentry? the Labor Market for Released Prisoners in PostIndustrial America, Sage, Los Angeles, CA, pp. 117-118.

Hu, L. T. and Bentler, P. M. (1999), "Cutoff criteria for fit indexes in covariance structure analysis: Conventional criteria versus new alternatives", Structural Equation Modeling: A Multidisciplinary Journal, Vol. 6 No. 1, pp. 1-55.

Jackson, J.W. (1993), "Realistic group conflict theory: a review and evaluation of the theoretical and empirical literature", Psychological Record, Vol. 43 No. 3, pp. 395-415.

Jackson, L. and Essess, V.M. (2000), "Effects of perceived economic consequences on people's willingness to help empower immigrants", Group Processes and Intergroup Relations, Vol. 3 No. 4, pp. 419-435.

Jamieson, D. (2014), Reason in a Dark Time: why the StruggleagainstClimate Change Failed and What It Means for Our Future, Oxford University Press, New York, NY.

Kinder, D.R. and Sears, D.O. (1981), "Symbolic racism versus racial threats to the good life", Journal of Personality and Social Psychology, Vol. 40 No. 3, pp. 414-431.

Levashina, J. and Campion, M. (2009), "Expected practices in background checking: review of the human resource management literature", Employee Responsibilities and Rights Journal, Vol. 21 No. 3, pp. 231-249.

Mason, W. and Suri, S. (2012), "Conducting behavioral research on amazon's mechanical turk", Behavior Research Methods, Vol. 44 No. 1, pp. 1-23.

Mathieu, J.E., Gilson, L.L. and Ruddy, T.M. (2006), "Empowerment and team effectiveness: an empirical test of an integrated model", The Journal of Applied Psychology, Vol. 91 No. 1, pp. 97-108.

Mill, J.S. (1859), On Liberty, 2nd Ed., John W. Parker and Son, London.

Pager, D. (2003), "The mark of a criminal record", American Journal of Sociology, Vol. 108 No. 5, pp. 937-975.

Pager, D. (2007), Marked: Race, Crime, and Finding Work in an Era of Mass Incarceration, University of Chicago Press, Chicago, IL.

Pager, D., Western, B. and Sugie, N. (2009), "Sequencing disadvantage: barriers to employment facing young black and white men with criminal records", Annals of the American Academy of Political and Social Sciences, Vol. 623 No. 1, pp. 195-213.

Paolacci, G., Chandler, J. and Ipeirotis, P.G. (2010), "Running experiments on amazon mechanical turk", Judgment and Decision Making, Vol. 5 No. 5, pp. 411-419.

Pastore, A.L. and Maguire, K. (Eds) (2006), "Sourcebook of Criminal Justice Statistics", Table 6.1.2006 and Table 6.28.2006, available at: www.albany.edu/sourcebook/pdf/t612006.pdf and www. albany.edu/sourcebook/pdf/t6282006.pdf(accessed 14 June 2018).

Ployhart, R.E. and Ryan, A.M. (1997), "Toward an explanation of applicant reactions: an examination of organizational justice and attribution frameworks", Organizational Behavior and Human Decision Processes, Vol. 72 No. 3, pp. 308-335. 
Schmitt, J. and Warner, K. (2010), Ex-Offenders and the Labor Market, Center for Economic Research, Washington, DC, available at: www.cepr.net/documents/publications/ex-offenders-2010-11.pdf (accessed 14 June 2018).

Sherif, M., Harvey, O.J., White, B.J., Hood, W.R. and Sherif, C. (1961), Intergroup Conflict and Cooperation: The Robbers' Cave Experiment, Institute of Group Relations, University of OK, Norman, OK.

Sidanius, J. and Pratto, F. (1999), Social Dominance: an Intergroup Theory of Social Hierarchy and Oppression, Cambridge University Press, Cambridge.

Simonson, J. (2006), "Rethinking 'rational discrimination' against ex-offenders", Georgetown Journal on Poverty Law and Policy, Vol. 13 No. 2, pp. 283-311.

Stoll, M. (2009), "Ex-offenders, criminal background checks, and racial consequences in the labor market", The University of Chicago Legal Forum, Vol. 2009 No. 1, pp. 381-419.

Supphellen, M., Kvitastein, O. and Johansen, S. (1997), "Projective questioning and ethnic discrimination: a procedure for measuring employer bias", Public Opinion Quarterly, Vol. 61 No. 1, Special Issue on Race, pp. 208-224.

Tajfel, H. and Turner, J.C. (1986), "The social identify theory of intergroup behavior", in Worchel S. and Austin W.G.(Eds), Psychology of Intergroup Relations, Nelson-Hall, Chicago, IL, pp. 7-24.

Tajfel, H., Turner, J.C., (1979), "An integrative theory of intergroup conflict", in Austin W G. and Worchel S. (Eds), The Social Psychology of Intergroup Relations, Brooks/Cole, Monterey, CA, reprinted in Hogg, M.A. and Abrams, D. (2001), Intergroup Relations, Psychology Press, New York, NY, pp. 33-47.

United States Census Bureau (2014), "Frequently occurring surnames from the census 2000, file A: top 1000 names", data set available at: www.census.gov/topics/population/genealogy/data/ 2000_surnames.html (accessed 14 June 2018).

Further reading

BJS (2008), "Bureau of justice statistics, strategic plan FY 2005-2008”, available at: www.bjs.gov/ content/pub/pdf/bjssp08.pdf (accessed 14 June 2018).

Corresponding author

Barry Goldman can be contacted at: bgoldman@eller.arizona.edu

Appendix A

This appendix contains materials used in Study 1.

\section{A.1 experiment}

scenario

In this experiment, imagine that you are a hiring manager at Lanover University, a large and growing private online university. As part of your work, you posted a job description for an open position. Itis important to fill this position with a qualified candidate. Until you do so, everyone on the team (including you) has more work than they can effectively handle in the work week. On the other hand, if you make a hiring mistake, things will get even worse for the team.

In this experiment, you will review and rate an application for the position.

\section{A.2 Job description}

\section{Market research analyst}

Position summary. The primary focus of the market research analyst is to execute market research projects under the direction of the lead market research analyst. 
Responsibilities.

- identify market research solutions to businessproblems;

- design, execute and present market research projects; and

- be a knowledgeable resource and consultant for internal clients about market research.

Required qualifications.

- $\quad 3 \mathbf{p}$ years' experience in designing, developing and executing market research projects;

- knowledge and experience using statistical software; and

- bachelor degree in related field.

Required competencies.

- ability to think strategically and encourage strategic dialogue;

- understand principles of marketing;

- strong written and verbal communication skills; and

- strong organizational, project management and interpersonalskills.

\section{A.3 Applicant resume}

James Smith

Market Research Professional.

\section{Summary}

Market research professional dedicated to providing outstanding results to internal and external clients.

\section{Experience}

Marketresearchanalyst.JBFoods

2014-Present (1 year).

Food industry market research analyst for gourmet brand.

- Contributor advertising impact study for a new product.

- Designed and executed market research, including data analysis with statistical software.

- Provided actionable recommendations to marketing team.

- Assisted in product market forecasting.

- Provided key insights/trends from secondary data reports.

- Measured impact of new competition in the smoked meats market.

Market research analyst

University of Alabama

2012-2014 (2 years).

Research analyst for alumni office.

- Responsible for creating surveys to support development of new alumni services.

- Created research reports from surveyresults.

- Coded survey responses, conducted focus groups, and developed market data collection campaigns. 


\section{Education}

University of Alabama.

BA, Communication.

2012.

\section{A.4 Comprehension checks}

Two multiple-choice comprehension checks were displayed after participants read the description of their role and the job description. The choices are in parentheses following each question and the correct answer is initalics:.

- You are playing the part of a hiring manager at which of the following? (an advertising agency, an online university, a pharmaceutical company, a trucking company, a restaurant chain)

- What is the title of the job? (university instructor, chemist (senior), market research analyst, adverstising analyst, HR director)

One or both of these checks were failed by 136 participants. These participants were excused from the experiment.

The final comprehension check was displayed after participants read the job application and rated the job applicant:

- What were the results of the applicant's criminal background check? (no information about a criminal background check was provided, the criminal background check found a felony conviction, the criminal background check did not find any convictions)

This check was failed by 18 participants who were excused from the experiment.

\section{Appendix B}

This appendix includes the measures of mediators used in Study 2. Responses were recorded on a seven-point Likert scale. The scale names (e.g. Harm) were not displayed to participants.

\section{Harm}

The sentences below state possible reasons why hiring this person might harm the organization or the people in it. Please indicate how much you agree or disagree that each statement is a reason to NOT hire this person:

- He may cause serious harm or injury to the interests of the organization or its employees.

- He may commit a criminal offense at work.

- He is likely to hurt the reputation of the organization.

\section{Poor character}

The sentences below state possible concerns about this person's character. Please indicate how much you agree or disagree that each statement is a reason to NOT hire this person:

- He is likely to beunreliable.

- He is likely to beuntrustworthy.

- He is likely to bedishonest. 
Offense

The sentences below state possible reasons why other people in the organization might be offended by hiring this person. Please indicate how much you agree or disagree that each statement is a reason to NOT hire this person:

- He may seriously offend other employees, even if he does not actually harm them.

- I think most people in the organization would be offended if we employed him.

- It would bother my coworkers to know our organization would hire this kind of person.

\section{Moralism}

The sentences below state possible moral concerns about hiring this person. Please indicate how much you agree or disagree that each statement is a reason to NOT hire this person:

- To me, he would be a morally inappropriate representative of the organization's values.

- I believe it is morally incorrect to hire this person.

- I would be uncomfortable around him because his morals are low. 